\title{
Carotid body chemoreceptors, sympathetic neural activation, and cardiometabolic disease
}

\author{
Rodrigo Iturriaga ${ }^{1 *}$, Rodrigo Del Rio ${ }^{2,3}$, Juan Idiaquez ${ }^{4}$ and Virend K. Somers ${ }^{5}$
}

\begin{abstract}
The carotid body (CB) is the main peripheral chemoreceptor that senses the arterial $\mathrm{PO}_{2}, \mathrm{PCO}_{2}$ and $\mathrm{pH}$. In response to hypoxemia, hypercapnia and acidosis, carotid chemosensory discharge elicits reflex respiratory, autonomic and cardiovascular adjustments. The classical construct considers the CB as the main peripheral oxygen sensor, triggering reflex physiological responses to acute hypoxemia and facilitating the ventilatory acclimation to chronic hypoxemia at high altitude. However, a growing body of experimental evidence supports the novel concept that an abnormally enhanced CB chemosensory input to the brainstem contributes to overactivation of the sympathetic nervous system, and consequent pathology. Indeed, the CB has been implicated in several diseases associated with increases in central sympathetic outflow. These include hypertension, heart failure, sleep apnea, chronic obstructive pulmonary disease and metabolic syndrome. Indeed, ablation of the CB has been proposed for the treatment of severe and resistant hypertension in humans. In this review, we will analyze and discuss new evidence supporting an important role for the CB chemoreceptor in the progression of autonomic and cardiorespiratory alterations induced by heart failure, obstructive sleep apnea, chronic obstructive pulmonary disease and metabolic syndrome.
\end{abstract}

Keywords: Autonomic dysfunction, Carotid body, Heart failure, Metabolic syndrome, Obstructive sleep apnea, Sympathetic activation

\section{Background}

The carotid body (CB) is a polymodal chemoreceptor located in the carotid bifurcation, which is activated by hypoxemia, hypercapnia, acidosis, reduction of arterial blood flow, temperature change and low levels of glucose [1-4]. Reflex cardiorespiratory responses are characterized by hyperventilation and increased sympathetic discharge to the vascular beds and the heart. Tachycardia associated with hyperventilation in turn augments cardiac output, acutely raising arterial blood pressure. The CB chemoreceptor (glomus or type I) cells, which make synaptic contact with the nerve terminals of the chemosensory petrosal neurons, are considered the sensors of the natural stimuli [1-4].

\footnotetext{
*Correspondence: riturriaga@bio.puc.cl

${ }^{1}$ Laboratorio de Neurobiología, Facultad de Ciencias Biológicas,

Pontificia Universidad Católica de Chile, Santiago, Chile

Full list of author information is available at the end of the article
}

The current model of $\mathrm{CB}$ chemoreception holds that hypoxia and hypercapnia-acidosis close voltage independent (TASK) and voltage-dependent $\mathrm{K}^{+}$channels, leading to glomus cell depolarization, entry of $\mathrm{Ca}^{2+}$ through L-type $\mathrm{Ca}^{2+}$ channels, and release of one or more excitatory transmitters, which increases the discharges of the nerve endings of chemosensory neurons [2-5]. Several molecules are present in glomus cells, but acetylcholine and adenosine triphosphate fulfill most of the criteria to be considered as excitatory transmitters between the glomus cells and petrosal nerve endings [3-5]. However, other molecules such as dopamine, histamine, nitric oxide (NO), carbon monoxide, $\mathrm{H}_{2} \mathrm{~S}$, and endothelin-1 (ET-1) modulate the chemosensory process by producing tonic actions on $\mathrm{CB}$ blood vessels or direct effects on glomus cells [3-5]. More recently, proinflammatory cytokines such as interleukin $1 \beta$, interleukin 6 and TNF- $\alpha$ have been found to modulate CB chemoreception in rats [6-8]. 
The classical physiological paradigm considers the $\mathrm{CB}$ as the main oxygen sensor, triggering ventilatory responses to acute hypoxemia and modulating the ventilatory acclimation to high altitude. Notwithstanding, a growing body of evidence involved the $\mathrm{CB}$ in several sympathetic-mediated human diseases [8-17]. Indeed, selective ablation of the $\mathrm{CB}$ improves survival in heart failure (HF) experimental models [10, 11], prevents the development of insulin resistance and hypertension in rats fed with a high fat diet [18], and attenuates the hypertension induced by chronic intermittent hypoxia in a rat model of obstructive sleep apnea [19].

\section{The carotid body and heart failure}

Heart failure (HF) is characterized by frequent hospitalizations and high mortality risk. Accordingly, $\mathrm{HF}$ is considered a major health problem, affecting $20 \%$ of the adult population $[20,21]$. The pathophysiology of HF is characterized by a progressive decrease in cardiac function, which severely impacts the blood supply to several vascular beds [22-24]. Two main characteristics of HF are the presence of autonomic imbalance and disordered breathing patterns, both of which has been shown to be strongly associated with the degree of cardiac failure [11, 25-27]. Indeed, the contribution of heightened CB chemoreflex drive and excessive sympathetic outflow to the development and progression of HF has been demonstrated in both humans and experimental animal models $[13,27,28]$. Indeed, an enhanced CB chemoreflex drive has been shown to play a key role in the progression of cardiorespiratory disorders in $\mathrm{HF}[11,29]$, and high $\mathrm{CB}$ chemosensitivity correlates strongly with high mortality risk and poor prognosis in patients with HF [30]. In experimental HF, the $\mathrm{CB}$ chemosensory activity is tonically elevated leading to sympatho-excitation and destabilization of breathing [13, 27, 31].

The physiological mechanisms underlying cardiorespiratory alterations in HF are not fully understood. The most widely accepted model of $\mathrm{CB}$ chemoreflex regulation states that chemosensory nerve fibers from the $\mathrm{CB}$ project to the nucleus tractus solitarius (NTS), which integrates the $\mathrm{CB}$ afferent visceral sensory input. The NTS in turn sends efferent projections to the respiratory neuronal network and brainstem autonomic sympathetic nuclei, such as the rostral ventrolateral medulla (RVLM) [32]. It has been shown that in HF rats, the CB chemosensory discharge in normoxia is enhanced resulting in hyper-activation of pre-sympathetic neurons located in the RVLM, which finally leads to increased central sympathetic outflow [33]. Furthermore, Marcus et al. [27] showed that an augmented CB afferent activity triggered respiratory-sympathetic coupling in rabbits with
HF. Notably, selective ablation of the CB chemoreceptors decreased RVLM pre-sympathetic neuron activation, restored normal sympathetic outflow, and markedly reduced the incidence of oscillatory breathing patterns in HF (see Fig. 1). Additionally, if performed early during the progression of $\mathrm{HF}, \mathrm{CB}$ ablation reduced collagen deposition and fibrosis in the ventricular myocardium, decreased the number of cardiac arrhythmias, blunted cardiac function deterioration and strikingly improved survival of HF rats (Fig. 2). Together, these results strongly support a crucial role of the CB in the development of abnormal breathing patterns and increased sympathetic outflow, adding more stress to the failing heart, and ultimately leading to higher mortality risk.

The tonic hyper-activation of the $\mathrm{CB}$ chemoreceptor cells during HF appears to be a key step in disease progression. Identifying molecular mechanisms underlying $\mathrm{CB}$ chemoreceptor activation could therefore lead to novel future interventions intended to normalize $C B$ chemosensory activity in HF. Recently, Schultz and colleagues provided a comprehensive review on the plausible mechanisms underpinning the enhanced $\mathrm{CB}$ function in HF [34]. Due to the nature of HF, a chronic reduction in blood supply to several organs is expected during the progression of the disease. Thus, it has been hypothesized that blood flow restrictions to the $\mathrm{CB}$ region could play a role in inducing augmented $\mathrm{CB}$ chemosensory discharge in HF. Ding et al. [35] provide the first evidence showing that chronic blood flow restrictions to the $\mathrm{CB}$ in normal animals induced $C B$ chemorelfex activation. Indeed, reducing blood supply to the $\mathrm{CB}$ to a similar extent to flows observed in HF animals results in $\mathrm{CB}$ chemosensory potentiation and increases in renal sympathetic nerve activity [35]. Recently, the blood flow-sensitive transcription factor, Kruppel-like factor 2 (KLF-2), was shown to be constitutively expressed in the $\mathrm{CB}$, particularly in chemoreceptor cells [36]. Furthermore, KLF-2 expression in the CBs is markedly reduced during HF [36]. The viral transduction of KLF-2 in the CB of rabbits with HF normalizes $\mathrm{CB}$ function and reduces sympathetic outflow despite the chronic reduction of blood flow to the tissue [34]. In addition, other factors such as decreases in NO bioavailability and increases in local and systemic levels of angiotensin II also could contribute to an increased CB chemoreflex drive in HF. Furthermore, oxidative stress has been related to augmented $\mathrm{CB}$ discharge in HF, since genetic manipulation to increase superoxide dismutase within the CB tissue significantly reduced CB afferent activity [35]. Further studies are needed to uncover the role played by KLF-2 in the regulation of NO synthase expression as well as superoxide dismutase expression and local angiotensin II production in the $\mathrm{CB}$ during $\mathrm{HF}$. 


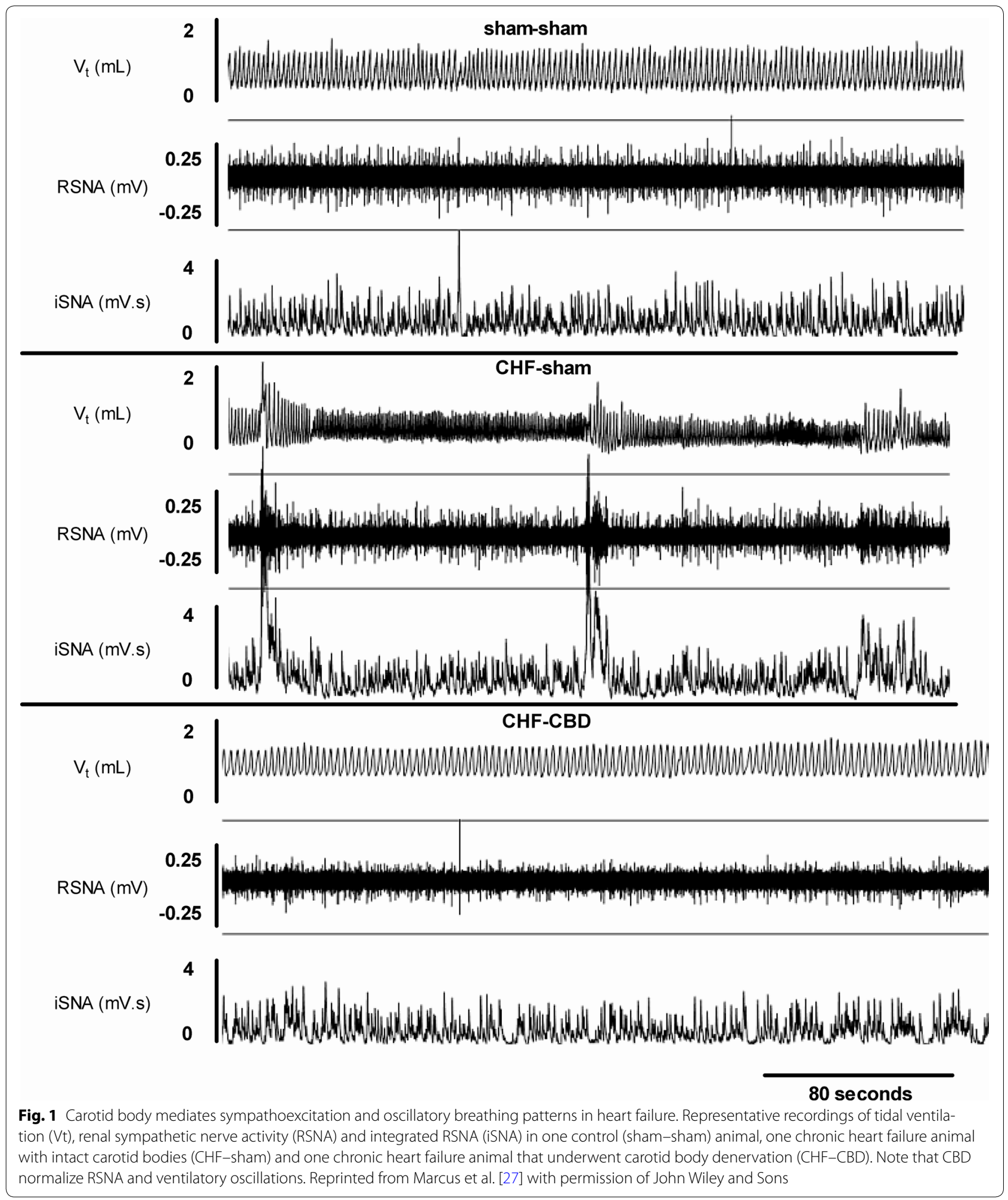

The carotid body and obstructive sleep apnea Obstructive sleep apnea (OSA) is elicited by repeated total or partial occlusions of the upper airway, and is associated with daytime sleepiness, fatigue, depressed mood, and cognitive alterations [37, 38]. Several epidemiological studies have demonstrated that OSA is an 

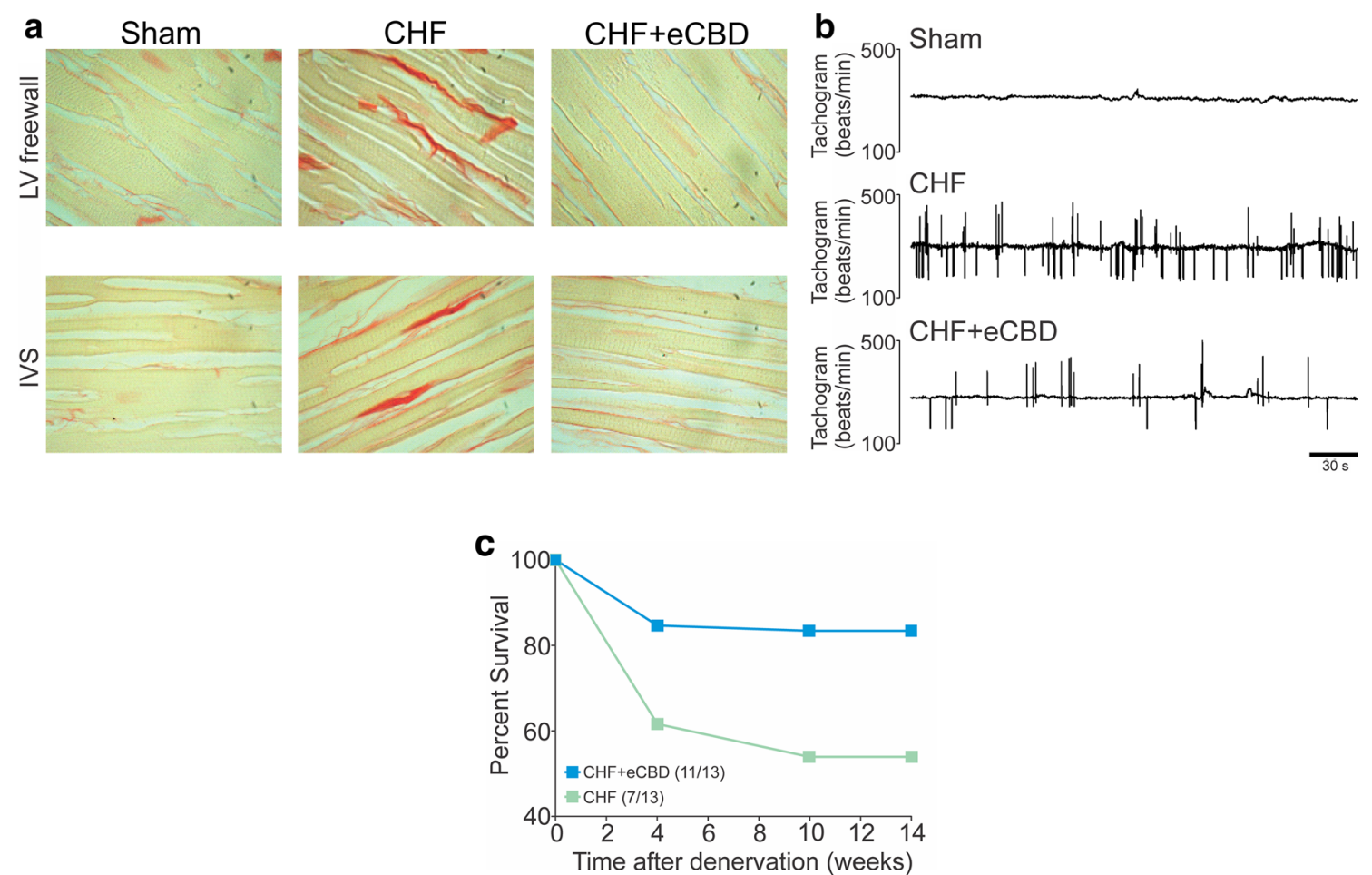

Fig. 2 Carotid Body denervation reduced myocardial fibrosis and cardiac arrhythmias and improved survival in heart failure rats. a Rats with chronic heart failure (CHF) and with CHF and carotid body denervation (eCBD) displayed tissue fibrosis in noninfarcted areas. The left ventricle (LV) freewall and the interventricular septum (IVS) obtained from CHF rats showed a marked collagen deposition. Selective eCBD significantly reduced cardiac fibrosis in the LV-freewall and in the IVS. b Representative tachograms showing arrhythmic episodes in a CHF rat and a marked decreased in the arrhythmic events in CHF+eCBD rat. c Rats that underwent eCBD showed reduced mortality rate compared to CHF rats with functional CBs. Modified from Del Rio et al. [10], with permission of Elsevier

independent risk factor for the development and progression of systemic hypertension, showing a positive correlation between the apnea/hypopnea index and the severity of hypertension [38-41]. The repeated episodes of airflow obstruction during sleep produces cyclic intermittent hypoxemia and hypercapnia, which stimulate the $\mathrm{CB}$ eliciting reflex ventilatory, sympathetic and hypertensive responses. Among these disturbances, chronic intermittent hypoxemia $(\mathrm{CIH})$ is considered the main factor related to systemic hypertension [17, 42-48].

Although the link between OSA and hypertension is well established, the pathogenic mechanisms underlying the onset and maintenance of the hypertension are not entirely known. It has been proposed that $\mathrm{CIH}$ elicits oxidative stress, inflammation, and sympathetic hyperactivity, which leads to endothelial dysfunction and hypertension $[8,17,43,49,50]$. However, studies performed in OSA patients are limited by degree of invasiveness, and because OSA patients often present concomitant comorbidities (such as obesity and metabolic alterations), which themselves increase cardiovascular risk. Therefore, casual relationships between OSA and associated disease conditions are not well demarcated. On the other hand, experimental models of rodents exposed to $\mathrm{CIH}$ reproduce several cardiovascular pathologic features of OSA including hypertension and sympathetic hyperactivity $[8$, 19, 51-54, 56-62].

Patients with recently diagnosed OSA show enhanced vasopressor and ventilatory responses to acute hypoxemia [63-66], and manifest sympathetic hyperactivity evidenced by an increased muscle sympathetic neural activity [67] and higher levels of urinary norepinephrine [68]. Similarly, rodents exposed to $\mathrm{CIH}$ have enhanced cardiorespiratory and sympathetic responses to hypoxia, and develop systemic hypertension [5, 69-74]. Furthermore, both OSA patients and animals exposed to $\mathrm{CIH}$ show reduction of baroreflex gain and alterations of heart rate variability towards a predominance of sympathetic drive $[51,65,75-79]$. Thus, it is likely that enhanced sympathetic activity along with reduction of baroreflex gain may contribute to the rise of arterial blood pressure following $\mathrm{CIH}$. The enhanced cardiorespiratory responses to acute hypoxemia found in patients with recently diagnosed OSA has been attributed to an enhanced hypoxic chemoreflex [63-66, 80], suggesting that the $C B$ is involved in the pathological alterations induced by OSA. 
Although Fletcher et al. [19] found that CB denervation prevented hypertension in rats exposed to $\mathrm{CIH}$, the contribution of the $\mathrm{CB}$ to the cardiovascular pathology induced by OSA was not considered. However, in the last decade the proposal that an abnormally enhanced $\mathrm{CB}$ chemosensory drive is involved in the progression of $\mathrm{CIH}$-induced hypertension has received substantial attention [43, 49, 58, 81]. Recordings of CB neural discharges in situ and in vitro have demonstrate that $\mathrm{CIH}$ selectively increases basal discharge in normoxia, and potentiates the chemosensory responses to acute hypoxia [18, 51, 52, 54-59, 78, 79] (see Fig. 3).

Reactive oxygen species (ROS) and reactive nitrogen species (RNS) have been implicated as mediators of cardiovascular and cognitive alterations in OSA patients [44, 82-85] and animal models [51, 52, 54, 55, 57, 59]. We tested the hypothesis that oxidative stress contributes to $\mathrm{CB}$ chemosensory potentiation and the progression of the hypertension in rats exposed to $\mathrm{CIH}$ [51]. We found that $\mathrm{CIH}$ increased plasma lipid peroxidation and formation of the oxidative stress marker 3-nitrotyrosine (3-NT) in the $\mathrm{CB}$. In addition, $\mathrm{CIH}$ enhanced $\mathrm{CB}$
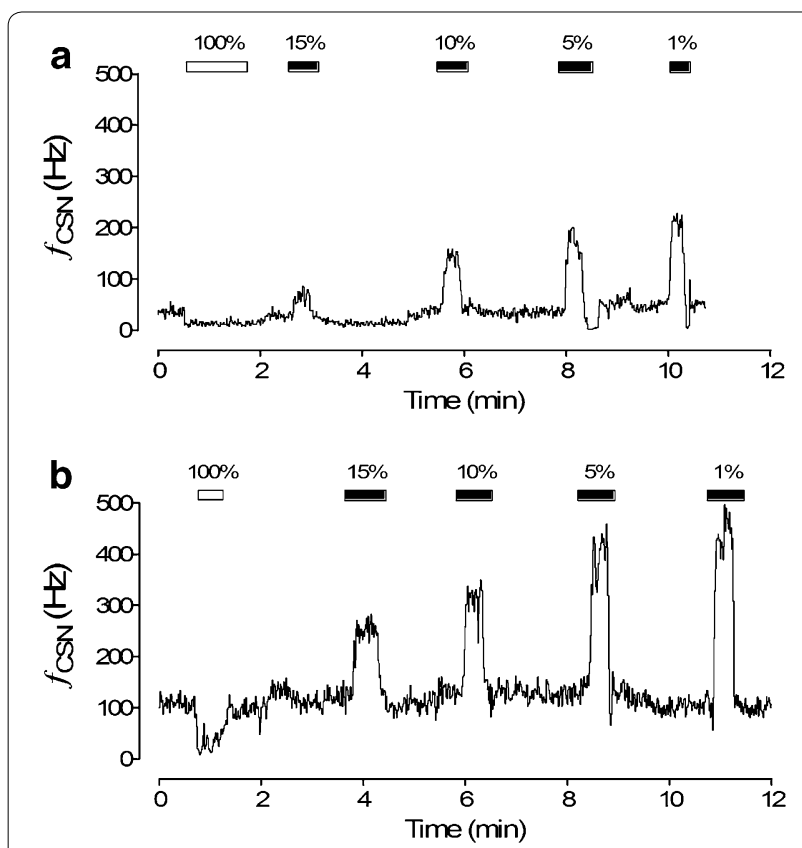

Fig. $3 \mathrm{ClH}$ increased basal carotid chemosensory discharges and induced a potentiation of chemosensory responses to acute hypoxia. The chemosensory responses to various levels of inspired $\mathrm{O}_{2}\left(\mathrm{PO}_{2} \approx 100-1 \%\right)$ were measured from one carotid sinus nerve of a sham rat (a) and from a rat exposed to cyclic hypoxic episodes $\left(\mathrm{PO}_{2}\right.$ to $35 \mathrm{mmHg}, 12$ times per $h$ during $\left.8 \mathrm{~h}\right)$ for 21 days. (b) $f_{\mathrm{csn}}$ frequency of carotid chemosensory discharges expressed in $\mathrm{Hz}$. Rats were anesthetized with sodium pentobarbitone (40 mg/kg ip) and breathed spontaneously room air. Reprinted from Iturriaga et al. [8] with permission of John Wiley and Sons chemosensory and ventilatory responses to hypoxia and elicited hypertension. Antioxidant treatment with ascorbic acid reduced the increased systemic and $\mathrm{CB}$ oxidative stress, normalized $C B$ chemoreflex function, and markedly reduced the elevated arterial blood pressure. Although, these results strongly suggest that CB chemosensory potentiation is mediated by oxidative stress, it is a matter of debate as to whether ROS per se may increase CB chemosensory discharge [86]. Thus, it is likely that other molecules downstream of ROS signaling mediate the CIH-induced effects of ROS on CB chemoreception. Among the molecules upregulated in the $\mathrm{CB}$ by $\mathrm{CIH}$, such as ET-1, VEGF and iNOS [52, 53, 79, 87, 89], proinflammatory cytokines have been proposed as mediators of the $\mathrm{CB}$ chemosensory potentiation induced by $\mathrm{CIH}[8$, $9,52,54,87,88,89]$. We found that $\mathrm{CIH}$ induced a ROSdependent increase in TNF- $\alpha$ and IL- $1 \beta$ levels in the CB, suggesting that these pro-inflammatory cytokines may mediate the ROS-induced CB potentiation [51, 52]. Furthermore, ibuprofen treatment prevented $\mathrm{CB}$ cytokine overexpression, as well as the enhanced hypoxic ventilatory response and the hypertension, but failed to block the enhanced CB chemosensory responses [54]. Thus, our studies suggest that upregulation of TNF- $\alpha$ and IL- $1 \beta$ in the $\mathrm{CB}$ induced by $\mathrm{CIH}$ is linked to oxidative stress, as well as to the enhanced $\mathrm{CB}$ chemosensory responsiveness to hypoxia, but the chemosensory potentiation does not depend on the increased TNF- $\alpha$ and IL- $1 \beta$ levels in the CB. However, pro-inflammatory cytokines contribute to enhance the hypoxic ventilatory response and to the hypertension induced by $\mathrm{CIH}$, suggesting that multiple mechanisms may participate in the cardiorespiratory alterations induced by $\mathrm{CIH}$.

\section{The carotid body and chronic obstructive pulmonary disease}

Chronic obstructive pulmonary disease (COPD) is a systemic disease that includes many extra pulmonary manifestations including systemic inflammation, cachexia, and muscle dysfunction [90]. Increased sympathetic activation in COPD is evident from increased plasma norepinephrine, and associated with increased plasma renin activity and aldosterone concentration [90]. Heightened muscle sympathetic nerve activity occurs in patients with chronic respiratory failure [91-93]. In COPD patients, coexistent hypoxemia and hypercapnia, activates peripheral chemoreceptors (hypoxemia) and central chemoreceptors (hypercapnia). Short-term oxygen supplementation reduces muscle sympathetic nerve traffic in these patients [91] suggesting that peripheral chemoreceptors are involved. Sympathetic activation in COPD may be also related to other conditions like arterial and cardiac baroreflex dysfunction, breathing patterns 
and metaboreflex excitation [94]. Indeed, slow breathing causes a drop of sympathetic overactivity in COPD [95], possibly improving baroreflex sensitivity and gas exchange. The peripheral chemoreceptors therefore are likely contributors to elevated muscle sympathetic nerve discharge in COPD [92].

\section{Metabolic alterations: a new role for the carotid body?}

Metabolic syndrome is a growing health problem worldwide, with a high prevalence and strong associations with cardiovascular risk and diabetes. Autonomic dysfunction, characterized by sympathetic hyperactivity, vagal impairment, and impaired baroreflex sensitivity are characteristics of the metabolic syndrome and of disease conditions where the CB may be implicated, such as hypertension [96-99]. In addition, patients with metabolic disorders also have increased levels of leptin, ROS and pro-inflammatory cytokines. It is conceivable that $\mathrm{CB}$ chemosensory function may be compromised in the metabolic syndrome. In fact, it is known that obesity increases adipokine levels (i.e. leptin, resistin, TNF- $\alpha$ and IL-6), which in turn may activate NADPH oxidase increasing superoxide radical production. Superoxide reacts with $\mathrm{NO}$ to form peroxynitrite, decreasing $\mathrm{NO}$ availability, which contributes to the endothelial dysfunction [100]. We found a marked increase of 3-NT in the $\mathrm{CB}$ from rats exposed to $\mathrm{CIH}$, which correlates with the enhanced chemosensory responses to hypoxia [51, 52], supporting the idea that oxidative-nitrosative stress plays a critical role in $\mathrm{CB}$ chemosensory potentiation induced by $\mathrm{CIH}[8,9$, 52, 53].

The notion that the $\mathrm{CB}$ is involved in the metabolic regulation of glucose and insulin is not new [12, 101]. Recently, Ribeiro et al. [18] studied the role played by the $\mathrm{CB}$ in a rat model of insulin resistance induced by high fatsucrose diets. They found that $\mathrm{CB}$ stimulation by insulin seems to be involved in the development of insulin resistance and hypertension. Bilateral CB denervation prevents diet-induced insulin resistance and hypertension, suggesting that insulin-induced $\mathrm{CB}$ chemosensory excitation is responsible for the increased sympathetic outflow, creating a positive feedback, which results in severe insulin resistance and hypertension. Furthermore, Porzionato et al. [14] suggested that the CB chemoreceptors are a link between the metabolic disorders and the effects of $\mathrm{CIH}$. Indeed, they proposed that "hyperleptinemia and $\mathrm{CIH}$ may be interrelated mechanisms of sympathoactivation through peripheral chemoreceptors, because $\mathrm{CIH}$ increases plasma leptin levels and leptin immunoreactivity in the CB". Recently, Trombetta el al. [102] found evidence that metabolic disorders may interact with OSA to potentiate the hypoxic chemoreflexes in humans. In fact, they reported that OSA patients with metabolic syndrome had a higher ventilatory response to hypoxia, and higher muscle sympathetic basal discharge in normoxia and in response to hypoxia, than OSA patients without a metabolic disorder, suggesting that metabolic syndrome could enhanced the CB chemoreflex drive. Similarly, Fenik et al. [103] found that rats exposed to $\mathrm{CIH}$ for 35 days showed progressively reduced responses to insulin, which disappeared after 35 days of normoxic exposure. They also found that treatment with losartan eliminated the effects of $\mathrm{CIH}$ on insulin release, suggesting a role for the angiotensin-catecholaminergic pathway. Although these new and provocative ideas suggest that metabolic alterations may enhance $\mathrm{CB}$ chemosensory responses to hypoxia and increase sympathetic outflow, direct recordings of $\mathrm{CB}$ chemosensory discharge in metabolically altered models are required to determine if metabolic alterations in and of themselves, do indeed increase $\mathrm{CB}$ chemosensory activity.

\section{Conclusions}

In summary, the available evidence suggests that the $\mathrm{CB}$ contributes to the development of autonomic alterations. Identification of those pathways underlying the contribution of the $\mathrm{CB}$ to hypertension induced by $\mathrm{CIH}$ will provide new insights into the pathogenesis of the cardiovascular alterations observed in OSA and other disease conditions. Furthermore, a mechanistic understanding of altered CB function in sympathetic-mediated diseases will be relevant to improve current treatment options and to develop new therapeutic strategies intended to reduce human disease progression.

\section{Abbreviations}

CB: carotid body; CODP: chronic obstructive pulmonary disease; ET-1 endothelein-1; HF: heart failure; iNOS: inducible nitric oxide synthase; IL-6: interleukin 6; IL-1 $\beta$ : interleukin 1 B; KLF-2: Krüppel-like factor 2; NO: nitric oxide; NTS: nucleus tractus solitarius; 3-NT: 3-nitrotyrosine; OSA: obstructive sleep apnea; $\mathrm{PO}_{2}$ : oxygen partial pressure; $\mathrm{PCO}_{2}$ : carbon dioxide partial pressure; ROS: reactive oxygen species; RNS: reactive nitrogen specie; RVLM: rostral ventrolateral medulla; TNF-a: tumor necrosis factor-a; VEGF: vascular endothelial growth factor.

\section{Author's contributions}

RI and RDR manuscript and figures preparation, editing of manuscript, final approval of article. JI, VKS manuscript editing, final approval of article. All authors read and approved the final manuscript.

\section{Author details}

${ }^{1}$ Laboratorio de Neurobiología, Facultad de Ciencias Biológicas, Pontificia Universidad Católica de Chile, Santiago, Chile. ${ }^{2}$ Laboratory of Cardiorespiratory Control, Centro de Investigación Biomédica, Universidad Autónoma de Chile, Santiago, Chile. ${ }^{3}$ Dirección de Investigación, Universidad Científica del Sur, Lima, Peru. ${ }^{4}$ Catedra de Neurología, Escuela de Medicina, Universidad de Valparaíso, Valparaíso, Chile. ${ }^{5}$ Division of Cardiovascular Diseases, Mayo Clinic, Rochester, MN, USA. 


\section{Acknowledgements}

RI supported by FONDECYT 1150040, RDR by FONDECYT 1140275. VKS is supported by National Heart Lung and Blood Institute NIH R01 HL65176, a component of the National Institutes of Health $(\mathrm{NIH})$ and the NIH Roadmap for Medical Research. Its contents are solely the responsibility of the authors and do not necessarily represent the official view of NCRR or NIH.

\section{Competing interests}

The other authors declare that they have no competing interests. VKS has served as a consultant for Respicardia, Sorin Inc., Ronda Grey, Glaxo, Price Waterhouse, Philips Respironics, U-Health and ResMed. Mayo Foundation has received a gift from the Phillips-Respironics Foundation for the study of sleep apnea and cardiovascular disease.

\section{Received: 24 November 2015 Accepted: 12 February 2016 Published online: 26 February 2016}

\section{References}

1. Gonzalez C, Almaraz L, Obeso A, Rigual R. Carotid body chemoreceptors: from natural stimuli to sensory discharges. Physiol Rev. 1994;74:829-98.

2. Pardal R, Lopez-Barneo J. Low glucose-sensing cells in the carotid body. Nat Neurosci. 2002;5:197-8.

3. Iturriaga R, Alcayaga J. Neurotransmission in the carotid body: transmitters and modulators between glomus cells and petrosal ganglion nerve terminals. Brain Res Rev. 2004;47:46-53.

4. Nurse CA. Neurotransmission and neuromodulation in the chemosensory carotid body. Autonom Neurosci Basic Clin. 2005;120:1-9.

5. Iturriaga R, Varas R, Alcayaga J. Electrical and pharmacological properties of petrosal ganglion neurons that innervate the carotid body. Respir Physiol Neurobiol. 2007;157:130-9.

6. Lam SY, Tipoe GL, Liong EC, Fung ML. Chronic hypoxia upregulates the expression and function of proinflammatory cytokines in the rat carotid body. Histochem Cell Biol. 2008;130:549-59.

7. Powell FL. Adaptation to chronic hypoxia involves immune cell invasion and increased expression of inflammatory cytokines in rat carotid body. Am J Physiol Lung Cell Mol Physiol. 2009;296:L156-7.

8. Iturriaga R, Moya EA, Del Rio R. Carotid body potentiation induced by intermittent hypoxia: implications for cardiorespiratory changes induced by sleep apnoea. Clin Exp Pharmacol Physiol. 2009;36:1197-204.

9. Iturriaga R, Andrade DC, Del Rio R. Enhanced carotid body chemosensory activity and the cardiovascular alterations induced by intermittent hypoxia. Front Physiol. 2014;5:468. doi:10.3389/fphys.2014.00468.

10. Del Rio R, Marcus NJ, Schultz HD. Carotid chemoreceptor ablation improves survival in heart failure: rescuing autonomic control of cardiorespiratory function. J Am Coll Cardiol. 2013;62:2422-30.

11. Del Rio R. The carotid body and its relevance in pathophysiology. Exp Physiol. 2015;100:121-3.

12. Koyama Y, Coker RH, Stone EE, Lacy DB, Jabbour K, Williams PE, Wasserman $\mathrm{DH}$. Evidence that carotid bodies play an important role in glucoregulation in vivo. Diabetes. 2000;49:1434-42.

13. Schultz HD, Sun SY. Chemoreflex function in heart failure. Heart Failure Rev. 2000;5:45-56.

14. Porzionato A, Macchi V, De Caro R. Role of the carotid body in obesityrelated sympathoactivation. Hypertension. 2013;61:e57.

15. Paton JF, Sobotka PA, Fudim M, Engleman ZJ, Hart EC, McBryde FD Abdala AP, Marina N, Gourine AV, Lobo M, Patel N, Burchell A, Ratcliffe $L$, Nightingale $A$. The carotid body as a therapeutic target for the treatment of sympathetically mediated diseases. Hypertension. 2013;61:5-13.

16. Somers VK, Dyken ME, Clary MP, Abboud FM. Sympathetic neural mechanisms in obstructive sleep apnea. J Clin Invest. 1999;96:1897-904.

17. Somers VK, White DP, Amin R, Abraham WT, Costa F, Culebras A, Daniels S, Floras JS, Hunt CE, Olson LJ, Pickering TG, Russell R, Woo M, Young T. Sleep apnea and cardiovascular disease: an American Heart Association. In collaboration with the National Heart, Lung, and Blood Institute National Center on Sleep Disorders Research NIH. J Am Coll Cardiol. 2008:52:686-717.
18. Ribeiro MJ, Sacramento JF, Gonzalez C, Guarino MP, Monteiro EC, Conde SV. Carotid body denervation prevents the development of insulin resistance and hypertension induced by hypercaloric diets. Diabetes. 2013;62:2905-16.

19. Fletcher EC, Lesske J, Behm R, Miller CC, Stauss H, Unger T. Carotid chemoreceptors, systemic blood pressure, and chronic episodic hypoxia mimicking sleep apnea. J Appl Physiol. 1992;72:1978-84.

20. Remme WJ, Swedberg K. Guidelines for the diagnosis and treatment of chronic heart failure. Eur Heart J. 2001;22:1527-60.

21. Lloyd-Jones DM, Larson MG, Leip EP, Beiser A, D'Agostino RB, Kannel WB, Murabito JM, Vasan RS, Benjamin EJ, Levy D. Lifetime risk for developing chronic heart failure: the Framingham heart study. Circulation. 2002;106:3068-72.

22. Pfeffer MA, Braunwald E. Ventricular remodeling after myocardial infarction. Circulation. 1990;81:1161-72.

23. Hanly PJ, Zuberi-Khokhar NS. Increased mortality associated with Cheyne-Stokes respiration in patients with congestive heart failure. Am J Respir Crit Care Med. 1996;153:272-6.

24. Cohn JN, Ferrari R, Sharpe N. Cardiac remodeling - concepts and clinical implications: a consensus paper from an international forum on cardiac remodeling. J Am Coll Cardiol. 2000;535:569-82.

25. Francis GS. The relationship of the sympathetic nervous system and the renin angiotensin system in congestive heart failure. Am Heart J. 1989;118:642-8

26. Holtz J. Pathophysiology of heart failure and the renin-angiotensinsystem. Basic Res Cardiol. 1993;88(Suppl1):183-201.

27. Marcus NJ, Del Rio R, Schultz HD. Central role of carotid body chemoreceptors in disordered breathing and cardiorenal dysfunction in chronic heart failure. Front Physiol. 2014;5:438. doi:10.3389/fphys.2014.00438.

28. Del Rio R, Marcus NJ, Schultz HD. Inhibition of hydrogen sulfide restores normal breathing stability and improves autonomic control during experimental heart failure. J Appl Physiol. 2013;114:1141-50.

29. Ponikowski P, Chua TP, Anker SD, Francis DP, Doehner W, Banasiak W, Poole-Wilson PA, Piepoli MF, Coats AJ. Peripheral chemoreceptor hypersensitivity: an ominous sign in patients with chronic heart failure. Circulation. 2001;104:544-9.

30. Giannoni A, Emdin M, Bramanti F, Ludice G, Francis DP, Barsotti A, Piepoli M, Passino C. Combined increased chemosensitivity to hypoxia and hypercapnia as a prognosticator in heart failure. J Am Coll Cardiol. 2009:53:1975-80.

31. Sun SY, Wang W, Zucker IH, Schultz HD. Enhanced activity of carotid body chemoreceptors in rabbits with heart failure: role of nitric oxide. J Appl Physiol. 1999;86:1273-82.

32. Abbott SB, DePuy SD, Nguyen T, Coates MB, Stornetta RL, Guyenet PG. Selective optogenetic activation of rostral ventrolateral medullary catecholaminergic neurons produces cardiorespiratory stimulation in conscious mice. J Neurosci. 2013;33:3164-377.

33. Del Rio R, Andrade DC, Marcus NJ, Schultz HD. Selective carotid body ablation in experimental heart failure: a new therapeutic tool to improve cardiorespiratory control. Exp Physiol. 2015;100:136-42.

34. Schultz HD, Marcus NJ, Del Rio R. Role of the carotid body chemoreflex in the pathophysiology of heart failure: a perspective from animal studies. Adv Exp Med Biol. 2015;860:167-85.

35. Ding Y, Li YL, Schultz HD. Role of blood flow in carotid body chemoreflex function in heart failure. J Physiol London. 2011;589:245-58.

36. Haack KK, Marcus NJ, Del Rio R, Zucker IH, Schultz HD. Simvastatin treatment attenuates increased respiratory variability and apnea/hypopnea index in rats with chronic heart failure. Hypertension. 2014;63:1041-9.

37. Idiaquez J, Santos I, Santin J, Del Rio R, Iturriaga R. Neurobehavioral and autonomic alterations in adults with obstructive sleep apnea. Sleep Med. 2014;15:1319-23. doi:10.1016/j.sleep.2014.05.030.

38. Eckert DJ, Malhotra A. Pathophysiology of adult obstructive sleep apnea. Proc Am Thorac Soc. 2008;5:144-53.

39. Marin JM, Carrizo SJ, Vicente E, Agusti AGN. Long term cardiovascular outcomes in men with obstructive sleep apnoea-hypopnoea with or without treatment with continuous positive airway pressure: an observational study. Lancet. 2005;65:1046-53.

40. Peppard PE, Young T, Palta M, Skatrud J. Prospective study of the association between sleep-disordered breathing and hypertension. N Engl J Med. 2000;342:1378-84 
41. Young T, Palta M, Dempsey J, et al. The occurrence of sleep-disordered breathing among middle-aged adults. N Engl J Med. 1993;328:1230-5.

42. Arnardottir ES, Mackiewicz M, Gislason T, Teff KL, Pack Al. Molecular signatures of obstructive sleep apnea in adults: a review and perspective. Sleep. 2009;32:447-70.

43. Dempsey JA, Veasey SC, Morgan BJ, O'Donnell CP. Pathophysiology of sleep apnea. Physiol Rev. 2010;90:47-112.

44. Gozal D, Kheirandish-Gozal L. Cardiovascular morbidity in obstructive sleep apnea, oxidative stress, inflammation, and much more. Am J Respir Crit Care Med. 2008;177:369-75.

45. Iturriaga R, Del Rio R, Rey S. Cardiovascular and ventilatory acclimatization induced by chronic intermittent hypoxia: a role for the carotid body in the pathophysiology of sleep apnea. Biol Res. 2005;38:335-40.

46. Iturriaga R, Del Rio R. Oxidative stress in the carotid body: Implications for the cardioventilatory alterations induced by obstructive sleep apnea. In: Lushchak VI, Gospodaryov DV, editors. Oxidative stress and diseases: NTECH Open Access Publisher, http://www.intechweb.org 71-86, 2012.

47. Lavie L. Obstructive sleep apnoea syndrome-an oxidative stress disorder. Sleep Med Rev. 2003;7:35-51.

48. Lévy P, Pépin JL, Arnaud C, Tamisier R, Borel JC, Dematteis M, GodinRibuot D, Ribuot C. Intermittent hypoxia and sleep-disordered breathing: current concepts and perspectives. Eur Respir J. 2008;32:1082-95.

49. Garvey JF, Taylor CT, McNicholas WT. Cardiovascular disease in obstructive sleep apnoea syndrome: the role of intermittent hypoxia and inflammation. Eur Respir J. 2009;33:1195-205.

50. Ryan S, Taylor CT, McNicholas WT. Systemic inflammation: a key factor in the pathogenesis of cardiovascular complications in obstructive sleep apnoea syndrome? Thorax. 2009;64:631-6.

51. Del Rio R, Moya EA, Iturriaga R. Carotid body and cardiorespiratory alterations in intermittent hypoxia: the oxidative link. Eur Respir J. 2010;36:143-50.

52. Del Rio R, Moya EA, Iturriaga R. Differential expression of pro-inflammatory cytokines, endothelin-1 and nitric oxide synthases in the rat carotid body exposed to intermittent hypoxia. Brain Res. 2011;1395:74-85.

53. Del Rio R, Moya EA, Muñoz C, Arias P, Court FA, Iturriaga R. Chronic intermittent hypoxia-induced vascular enlargement and VEGF upregulation in the rat carotid body is not prevented by antioxidant treatment. Am J Physiol Lung Cell Moll Physiol. 2011;301:L702-11.

54. Del Rio R, Moya EA, Parga MJ, Madrid C, Iturriaga R. Carotid body inflammation and cardiorespiratory alterations in intermittent hypoxia. Eur Respir J. 2012;39:1492-500.

55. Dumitrascu R, Heitmann J, Seeger W, Weissmann N, Schulz R. Obstructive sleep apnea, oxidative stress and cardiovascular disease: lessons from animal studies. Oxid Med Cell Longev. 2013. http://dx.doi. org/10.1155/2013/234631

56. Peng YJ, Overholt JL, Kline D, Kumar GK, Prabhakar NR. Induction of sensory long-term facilitation in the carotid body by intermittent hypoxia: implications for recurrent apneas. Proc Natl Acad Sci USA 2003;00:10073-8.

57. Peng YJ, Prabhakar NR. Reactive oxygen species in the plasticity of breathing elicited by chronic intermittent hypoxia. J Appl Physiol. 2003;94:2342-9.

58. Peng YJ, Prabhakar NR. Effect of two paradigms of chronic intermittent hypoxia on carotid body sensory activity. J Appl Physiol. 2004;96:1236-42.

59. Peng YJ, Nanduri J, Yuan G, Wang N, Deneris E, Pendyala S, Natarajan V, Kumar GK, Prabhakar NR. NADPH oxidase is required for the sensory plasticity of the carotid body by chronic intermittent hypoxia. J Neurosci. 2009:29:4903-10.

60. Prabhakar NR, Peng YJ, Jacono FJ, Kumar GK, Dick TE. Cardiovascular alterations by chronic intermittent hypoxia: importance of carotid body chemoreflexes. Clin Exp Pharmacol Physiol. 2005;32:447-9.

61. Prabhakar NR, DickTE, Nanduri J, Kumar GK. Systemic, cellular and molecular analysis of chemoreflex-mediated sympathoexcitation by chronic intermittent hypoxia. Exp Physiol. 2007;92:39-44.

62. Schulz R, Eisele HJ, Murzabekova G, Weissmann N. Sleep apnea and cardiovascular disease-results from animal studies. Pneumologie. 2008;62:18-22.
63. Narkiewicz K, van de Borne PJ, Cooley RL, Dyken ME, Somers VK. Sympathetic activity in obese subjects with and without obstructive sleep apnea. Circulation. 1998;98:772-6.

64. Narkiewicz K, van de Borne PJ, Montano N, Dyken ME, Phillips BG, Somers VK. Contribution of tonic chemoreflex activation to sympathetic activity and blood pressure in patients with obstructive sleep apnea. Circulation. 1998:97:943-5.

65. Narkiewicz K, Montano N, Cogliati C, van de Borne PJ, Dyken ME, Somers VK. Altered cardiovascular variability in obstructive sleep apnea. Circulation. 1998;98:1071-7.

66. Narkiewicz K, van de Borne PJ, Pesek CA, Dyken ME, Montano N, Somers VK. Selective potentiation of peripheral chemoreflex sensitivity in obstructive sleep apnea. Circulation. 1999;99:1183-9.

67. Somers VK, Dyken ME, Clary MP, Abboud FM. Sympathetic neural mechanisms in obstructive sleep apnea. J Clin Invest. 1995;96:1897-904.

68. Dimsdale JE, Coy T, Ziegler MG, Ancoli-Israel S, Clausen J. The effect of sleep apnea on plasma and urinary catecholamines. Sleep. 1995;18:377-81.

69. Dick TE, Hsieh YH, Wang N, Prabhakar N. Acute intermittent hypoxia increases both phrenic and sympathetic nerve activities in the rat. Exp Physiol. 2007;92:87-97.

70. Feng J, Chen BY, Cui LY. Carotid body-mediated changes of sympathetic nerve and their relationships with hypertension. Chin Med J. 2008:121:1732-5.

71. Greenberg HE, Sica A, Batson D, Scharf SM. Chronic intermittent hypoxia increases sympathetic responsiveness to hypoxia and hypercapnia. J Appl Physiol. 1999;86:298-305.

72. Huang J, Lusina S, Xie T, Ji E, Xiang S, Liu Y, Weiss JW. Sympathetic response to chemostimulation in conscious rats exposed to chronic intermittent hypoxia. Respir Physiol Neurobiol. 2009;166:102-6.

73. Reeves SR, Gozal E, Guo SZ, Sachleben LR, Brittian KR, Lipton AJ, Goza D. Effect of long-term intermittent and sustained hypoxia on hypoxic ventilatory and metabolic responses in the adult rat. J Appl Physiol. 2003;95:1767-74.

74. Zoccal DB, Simms AE, Bonagamba LG, Braga VA, Pickering AE, Paton JF, Machado $\mathrm{BH}$. Increased sympathetic outflow in juvenile rats submitted to chronic intermittent hypoxia correlates with enhanced expiratory activity. J Physiol London. 2008;586:3253-65.

75. Shiomi T, Guilleminault C, Sasanabe R, Hirota I, Maekawa M, Kobayashi T. Augmented very low frequency component of heart rate variability during obstructive sleep apnea. Sleep. 1996;119:370-7.

76. Lai CJ, Yang CCH, Hsu YY, Lin YN, Kuo TBJ. Enhanced sympathetic outflow and decreased baroreflex sensitivity are associated with intermittent hypoxia-induced systemic hypertension in conscious rats. J Appl Physiol. 2006;100:1974-82.

77. Lin M, Liu R, Gozal D, Wead WB, Chapleau MW, Wurster R, Cheng ZJ. Chronic intermittent hypoxia impairs baroreflex control of heart rate but enhances heart rate responses to vagal efferent stimulation in anesthetized mice. Am J Physiol Heart Circ Physiol. 2007;293:H997-1006.

78. Rey S, Del Rio R, Alcayaga J, Iturriaga R. Chronic intermittent hypoxia enhances cat chemosensory and ventilatory responses to hypoxia. J Physiol London. 2004;560:577-86.

79. Rey S, Tarvainen MP, Karjalainen PA, Iturriaga R. Dynamic time-varying analysis of heart rate and blood pressure variability in cats exposed to short-term chronic intermittent hypoxia. Am J Physiol Regul Integr Comp Physiol. 2008;295:R28-37.

80. Cistulli PA, Sullivan CE. Pathology of sleep apnea. In: Saunders NA, Sullivan CE, editors. Sleep and Breathing. New York: Marcel Decker; 1994. p. 405-48.

81. Weiss JM, Liu MDY, Huang J. Physiological basis for a causal relationship of obstructive sleep apnoea to hypertension. Exp Physiol. 2007;921:21-6.

82. Baguet JP, Barone-Rochette G, Tamisier R, Levy P, Pépin JL. Mechanisms of cardiac dysfunction in obstructive sleep apnea. Nat Rev Cardiol. 2012;9:679-88.

83. Christou IK, Moulas AN, Pastaka C, Gouroulianis KI. Antioxidant capacity in obstructive sleep apnea patients. Sleep Med. 2003:4:225-8.

84. Jelic S, Padeletti M, Kawut SM, Higgins C, Canfield SM, Onat D, Colombo PC, Basner RC, Factor P, LeJemtel TH. Oxidative stress, and repair 
capacity of the vascular endothelium in obstructive sleep apnea. Circulation. 2008;17:2270-8.

85. Chen L, Einbinder E, Zhang Q, Hasday J, Balke CW, Scharf SM. Oxidative stress and left ventricular function with chronic intermittent hypoxia in rats. Am J Respir Crit Care Med. 2005;172:915-20.

86. Gonzalez C, Agapito MT, Rocher A, Gonzalez-Martin MC, Vega-Agapito V, Gomez-Niño A, Rigual R, Castañeda J, Obeso A. Chemoreception in the context of the general biology of ROS. Respir Physiol Neurobiol. 2007;157:30-44.

87. Rey S, Corthorn J, Chacón C, Iturriaga R. Expression and immunolocalization of endothelin peptides and its receptors, ETA and ETB, in the carotid body exposed to chronic intermittent hypoxia. J Histochem Cytochem. 2007:55:167-74.

88. Lam SY, Tipoe GL, Liong EC, Fung ML. Differential expressions and roles of hypoxia-inducible factor-1alpha,-2alpha and-3alpha in the rat carotid body during chronic and intermittent hypoxia. Histol Histopathol. 2008;23:271-80.

89. Iturriaga R, Moya EA, Del Rio R. Inflammation and oxidative stress during intermittent hypoxia: the impact on chemoreception. Exp Physiol. 2015;100:149-55.

90. Andreas S, Anker SD, Scanlon PD, Somers VK. Neurohumoral activation as a link to systemic manifestation of chronic lung disease. Chest. 2005;128:3618-24.

91. Heindl S, Lehnert M, Criée CP, Hasenfuss G, Andreas S. Marked sympathetic activation in patients with chronic respiratory failure. Am J Respir Crit Care Med. 2001;164:597-601.

92. Fatouleh R, Macefield VG. Respiratory modulation of muscle sympathetic nerve activity is not increased in essential hypertension or chronic obstructive pulmonary disease. J Physiol London. 2011;589:4997-5006.

93. Macefield VG. Firing patterns of muscle vasoconstrictor neurons in respiratory disease. Front Physiol. 2012;3:153.

94. Van Gestel AJ, Steier J. Autonomic dysfunction in patients with chronic obstructive pulmonary disease (COPD). J Thorac Dis. 2010;2:215-22.
95. Raupach T, Bahr F, Herrmann P, Luethje L, Heusser K, Hasenfuss G, Bernardi L, Andreas S. Slow breathing reduces sympathoexcitation in COPD. Eur Respir J. 2008;32:387-92.

96. Lehnen AM, Leguisamo NM, Casali KR, Schaan BD. Progressive cardiovascular autonomic dysfunction in rats with evolving metabolic syndrome. Auton Neurosci. 2013;176:64-9.

97. Smith M, Minson CT. Obesity and adipokines: effects on sympathetic overactivity. J Physiol. 2012;590:1787-801.

98. Savransky V, Nanayakkara A, Li J, Bevans S, Smith PL, Rodriguez A, Polotsky VI. Chronic intermittent hypoxia induces atherosclerosis. Am J Respir Crit Care Med. 2007;175:1290-7.

99. ToschiDias E, Trombetta IC, Dias da Silva VJ, Maki-Nunes C, Cepeda FX, Alves MJ, Drager LF, Lorenzi-Filho G, Negrao CE, Rondon MU. Time delay of baroreflex control and oscillatory pattern of sympathetic activity in patients with metabolic syndrome and obstructive sleep apnea. Am J Physiol Heart Circ Physiol. 2013;304:H1038-44.

100. Fernández-Sánchez A, Madrigal-Santillán F, Bautista M, Esquivel-Soto J, Morales-González A, Esquivel-Chirino C, Durante-Montiel I, SánchezRivera G, Valadez-Vega C, Morales-González JA. Inflammation, oxidative stress and obesity. Int J Mol Sci. 2011;12:3117-312.

101. Nimbkar NV, Lateef F. Carotid body dysfunction: the possible etiology of non-insulin dependent diabetes mellitus and essential hypertension. Med Hypotheses. 2005;65:1067-75.

102. Trombetta IC, Maki-Nunes C, Toschi-Dias E, Alves MJ, Rondon MU, Cepeda FX, Drager LF, Braga AM, Lorenzi-Filho G, Negrao CE. Obstructive sleep apnea is associated with increased chemoreflex sensitivity in patients with metabolic Syndrome. Sleep. 2013;36:41-9. doi:10.5665/ sleep.2298.

103. Fenik VB, Singletary T, Branconi JL, Davies RO, Kubin L. Glucoregulatory consequences and cardiorespiratory parameters in rats exposed to chronic-intermittent hypoxia: effects of the duration of exposure and losartan. Front Neurol. 2012;3:51. doi:10.3389/fneur.2012.00051.

\section{Submit your next manuscript to BioMed Central and we will help you at every step:}

- We accept pre-submission inquiries

- Our selector tool helps you to find the most relevant journal

- We provide round the clock customer support

- Convenient online submission

- Thorough peer review

- Inclusion in PubMed and all major indexing services

- Maximum visibility for your research

Submit your manuscript at www.biomedcentral.com/submit

\section{() Biomed Central}

